\title{
Entrepreneurship and the Socio-Technical Chasm in a Lean Economy
}

\author{
Tawanna R. Dillahunt ${ }^{1}$, Vaishnav Kameswaran ${ }^{1}$, Desiree McLain ${ }^{1}$, \\ Minnie Lester ${ }^{2}$, Delores Orr ${ }^{2}$, Kentaro Toyama ${ }^{1}$ \\ University of Michigan School of Information ${ }^{1}$; Eastside Community Network ${ }^{2}$ \\ Ann Arbor, MI; Detroit, MI USA \\ \{tdillahu, vaikam,dyjm, toyama \}@umich.edu; mil714mnn@aol.com,dorr7568@gmail.com
}

\begin{abstract}
Online technologies are increasingly hailed as enablers of entrepreneurship and income generation. Recent evidence suggests, however, that even the best such tools disproportionately favor those with pre-existing entrepreneurial advantages. Despite intentions, the technology on its own seems far from addressing socio-economic inequalities. Using participatory action research, we investigated why this might be, in an intimate, close-up context. Over a 1-year period, wea collaborative team of university researchers and residents of Detroit's East Side-worked to establish a neighborhood tour whose initial goal was to raise supplementary income and fundraise for community block clubs. We found that in addition to technical requirements, such as communication tools, a range of non-technological efforts is needed to manage projects, build self-efficacy, and otherwise support community participants. Our findings widen Ackerman's “socio-technical gap" for some contexts and offer a counterpoint to overgeneralized claims about well-designed technologies being able to address certain classes of social challenges.
\end{abstract}

\section{ACM Classification Keywords}

H.5.m. Information Interfaces and Presentation: Misc.

\section{Author Keywords}

Entrepreneurship; Social-Technical Gap; Lean Economies

\section{INTRODUCTION}

Entrepreneurship can increase incomes, reduce unemployment, and spur innovation [55]. Digital technology platforms can enable entrepreneurship in ways that were not previously possible. For example, crowdfunding sites allow for easy fundraising, websites and blogs offer channels for publicity and marketing, social media make it easy to network, and payment systems simplify financial transactions [26]. Sharing economy platforms such as Lyft and Airbnb go a step further by providing comprehensive business infrastructures that individuals can plug into to begin earning.

Permission to make digital or hard copies of all or part of this work for personal or classroom use is granted without fee provided that copies are not made or distributed for profit or commercial advantage and that copies bear this notice and the full citation on the first page. Copyrights for components of this work owned by others than ACM must be honored. Abstracting with credit is permitted. To copy otherwise, or republish, to post on servers or to redistribute to lists, requires prior specific permission and/or a fee. Request permissions from permissions@acm.org.

CHI 2018, April 21-26, 2018, Montréal, QC, Canada.

Copyright is held by the owner/author(s). Publication rights licensed to ACM

ACM ISBN 978-1-4503-5620-6/18/04 ..\$15.00.

http://dx.doi.org/10.1145/3173574.3173814
Critics, however, have called into question what digital technology platforms actually do for minorities and lower-income people who hope to participate in entrepreneurship [22]. Entrepreneurship requires investment and a range of social factors, such as social capital $[9,47]$, that are known to be disproportionately less available for minority and lower-income entrepreneurs $[9,14]$. Although technology has been shown to support small- and medium-sized businesses in the context of the developing world [12], studies to understand how technology supports micro-enterprises in developed countries, particularly those facing socio-economic inequalities, are rare. This is true particularly among minorities and individuals living in low socio-economic status (SES) areas where access to family and friends to help finance a new business may be limited. In this work, we use the term "lean economies" to describe environments where community members manage slim resources innovatively and resiliently. ${ }^{1}$ Such inquiries are important given that racial minorities have been found to be funded less than others on crowdfunding sites [59]; similarly, Edelman and Luca found that in New York City, black hosts in Airbnb earned 12\% less than non-black hosts for the equivalent rental [20]. Likewise, Ge et al. have identified racial discrimination against passengers in Uber and Lyft [25].

If technology can support entrepreneurship, the support is uneven, often propagating or amplifying existing socio-economic inequalities [2, 69] and social injustices [19]. For those interested in addressing inequalities and injustices, e.g., [19, 22], this fact raises an immediate question: If digital tools alone are insufficient for a progressive boost to less advantaged groups, what else is required? The human-computer interaction (HCI) community is keenly aware of what Ackerman called the "social-technical gap" between social needs and technical possibility [1], but the vast majority of that discussion has focused on professional white-collar knowledge workers. We expand this theory to the context of lean economies, and to circumstances that appear to exhibit a broader and deeper socio-technical chasm.

In this study we applied a participatory action research paradigm $[31,37,50,71]$ to launch a new neighborhood tour on Detroit's East Side that successfully remunerated

\footnotetext{
${ }^{1}$ This borrowed term [54] was one that our community participants agreed to, in contrast to terms like "urban," "inner-city," or "disadvantaged," all of which were seen to have derogatory connotations.
} 
community participants who gave the tour. Our results provide insight into the mechanics of entrepreneurship in lean economies $^{2}$, enumerate the technical and non-technical requirements for success, and deepen the notion of Ackerman's "socio-technical gap," particularly with systems meant to address socio-economic inequalities. While our work uncovers the technical requirements, it also uncovers hidden, non-technological requirements for entrepreneurial success. These requirements are often glossed over in the rhetoric of technology-enabled entrepreneurship-particularly for entrepreneurs in this distinct context. In our analysis we found that entrepreneurship requires social support and direct interaction of a kind that seems well beyond the reach of any technologies on the horizon. These contributions have implications for both civic technologists and policy-makers hoping to support entrepreneurship in communities with lean economies.

\section{RELATED WORK}

Ackerman's seminal work identified the social-technical gap as one of the central intellectual challenges of ComputerSupported Cooperative Work (CSCW) [1]. He defined this gap as "the divide between what we know we must support socially and what we can support technically" [1, p.179]. For example, while platforms such as Uber and Airbnb can support specific aspects of system interactions such as not requiring their users to provide profile pictures to minimize discrimination [20,46], technology cannot address the social inhibitors such as racism or sexism directly [1]. The human-information sharing relationship is highly nuanced, flexible, and context-dependent [1]. In our work, we pose the question, "What are the full complements of technical and non-technical requirements for technology-driven entrepreneurship?"

These requirements are not well-understood outside of the professional white-collar knowledge work context, where resources are abundant, and therefore are not addressed by popular technology platforms $[48,58]$. Using Ackerman's framing, we also ask whether each of the requirements can in fact be supported by technology. For those requirements that can be supported, we identify how they can be improved; we question whether those requirements that cannot be supported are technological limitations or opportunities.

To answer these questions, we first start by discussing what is known about the requirements for successful entrepreneurship from prior literature. These requirements frame our study findings. Next, we discuss strategies for economic development in low-resource settings and draw from prior literature on business organization and on information and communication technologies and development (ICTD). We conclude by exploring how computer-mediated systems as presented in HCI have helped entrepreneurs to meet these requirements. Throughout this section, each of the entrepreneurial requirements discussed in related work is coded by a letter-number combination that is referred to in Table 1.

\footnotetext{
${ }^{2}$ We apply the ecosystem metaphor to entrepreneurship defined by Babson as "a holistic interaction of all elements required to sustain a system that promotes increasing numbers of companies growing at an increasingly faster pace" [21].
}

\section{Requirements for Entrepreneurship}

While Scott's general theory of entrepreneurship [66] is perhaps the most comprehensive, the theory focuses more on traits of the opportunity rather than those traits of the individual entrepreneur. Our study focused specifically on neighborhood tours and less on the emergence of entrepreneurial opportunities. Therefore, we leveraged Markman and Baron's person-entrepreneurship fit framework [47].

Markman and Baron used this framework to describe the match between individual traits—of (A) human capital, (A.1) self-efficacy, (A.2) social skills, (A.8) the ability to recognize opportunity, and (A.9) perseverance, and (B) social capitaland success as an entrepreneur (Table 1). In other words, the more an individual has these characteristics, the greater the chance of the individual succeeding as an entrepreneur. We review these requirements as identified in this framework.

Several of these traits have received considerable attention in entrepreneurship research. Human capital is critical for entrepreneurship [65]. It comprises qualities acquired prior to work-health, personality, and intelligence-as well as skills gained on the job-training and interpersonal relationships [65]. Self-efficacy is a person's belief in his or her ability to accomplish a specific task, and it affects how one approaches challenges and tasks [3]. Evidence suggests that successful entrepreneurship is strongly linked to self-efficacy [47]. Social skills, or the ability to effectively interact with others, is also especially critical for entrepreneurship [47].

Recognizing opportunities is associated with individual factors such as an individual's career experience [63]. Then, the ability to deal with uncertainty, to face challenges such as financial liabilities, and to perform under anxiety and stress are traits of perseverance. Perseverance is needed for an entrepreneur to be successful [47].

Finally, there is the social capital of social networks, institutional ties, and organizational positions, which together represent socio-technical elements that are highly nuanced, flexible, and context-dependent [1]. This provides entrepreneurs with increased potential for cooperation and enhanced access to information [47]. In this work, it is also relevant that minority entrepreneurs often start out at a disadvantage with regard to many of these qualities $[9,14]$.

\section{Strategies for Development in Low-resource Settings}

Results from a series of interviews with more than 75 small business and micro-finance experts, entrepreneurs, community development leaders, economic development officials and educators in New York and around the United States, suggest that individuals in low-resourced areas often gain confidence to become entrepreneurs after seeing the successful business of their friends, family, and community members [41]. However, members of lean economies have limited access to these mentors, which could lead to limited self-efficacy and reduced access to social capital as compared to those from more affluent economies. In addition, individuals in such environments typically have limited access to family and friends who could help finance a new business, have low savings and limited financial literacy skills, and poor credit histories [41]. While not 
explicitly noted in Markman and Barron [47], access to (E.1) funding at the outset, affords entrepreneurship socioeconomic mobility [24].

In addition, research exploring entrepreneurship in limitedresourced environments also suggests that the involvement of community organizations is important to the success of the entrepreneurial endeavor. Similarly, Casey found that community-based support significantly increases access to credit for entrepreneurial activities among lean entrepreneurs [9]. The need for community organization support inspired our methodology, which we discuss in the Methodology section.

\section{Entrepreneurship in $\mathrm{HCl}$ and CSCW}

Entrepreneurship in HCI and CSCW spans ICTD and nonICTD contexts. While entrepreneurship broadly has been discussed in the context of making $[45,67,68]$ and crowdfunding $[26,30,36,35,51]$, much of the entrepreneurship research exists in the context of rural micro-entrepreneurship (particularly in ICTD contexts) [58] and the technology needed to support existing micro entrepreneurs in moving their businesses online (e.g., [48]), and in the sharing economy [16, 17, 27, 38, 44, 52, 57, 61].

Entrepreneurship research in HCI and CSCW aims to: (1) facilitate forms of support for entrepreneurs to build and sustain ventures; (2) identify design implications for tools to support entrepreneurs' ability to take advantage of their social networks [35] and connect entrepreneurs to mentors [33], and (3) build tools to connect entrepreneurs to collective capital [40]. For example, crowdfunding literature describes how entrepreneurs use collaborative platforms to develop business strategies [51], generate ideas, raise funds [26], and gain publicity [26]. Entrepreneurs using these platforms report enhanced self-efficacy [30], networking [26], and skills [26] as a result of interacting with other people. Despite the support for non-traditional entrepreneurship in $\mathrm{HCI}$ and $\mathrm{CSCW}$, none of this work explicitly seeks to support a sustainable cycle of entrepreneurship.

\section{METHODOLOGY}

Action research was most appropriate for our inquiry because it is an applied research method that actively involves community members [58]. As an approach, it supported a way to gather intimate and specific knowledge about novice entrepreneurs and their early steps toward entrepreneurship [50, 71] while also enhancing the skills of the respective actors, supporting "practical problem solving," [37, p. 242] and broadening scientific knowledge.

The university researchers among us proposed neighborhood tours as an entrepreneurial activity given the minimal startup costs, the fact that neighborhood tours leverage local knowledge and do not require special training, and that the idea could lead to a sustainable business. As we found during a competitive analysis, at least a dozen tours operate in Detroit's downtown area on a regular basis, ranging in price from free to $\$ 65$ per person. The competitive advantage of our tour are that it is in a historic but less well-known part of the city; and it is given by long-time residents of the community who can speak to its past history.

\section{Participatory Action Research Approach}

We provided all necessary support to allow our community participants to pilot an entrepreneurial venture successfully. The primary activities involved a series of approximately monthly meetings, two rehearsal tours, and two pilot tours with real customers. Throughout, we worked with a local non-profit organization that was a respected and trusted source in the community [16]. This also allowed us to gain advance insight about working with community members, and to hold meetings in a trusted location within the community itself.

We met our research objectives along the way, and we collected data by participating in all aspects of the process, taking extensive field notes, and conducting ad hoc interviews throughout. We further took a participatory action research approach by inviting members of the community to be involved in all aspects of the research as well [31], from project design and implementation, to data collection and analysis. To the degree that our community participants provided substantial intellectual input to both tour development and the research, we have taken the further step-inspired by collaborative ethnography [42] - to co-author this paper with the two community participants who remained with the project until the conclusion of the pilot. Finally, all tour proceeds went back to these community participants and to their respective block clubs, or smaller neighborhood organizations that aim to improve the quality of life in their community.

\section{Research Setting}

Our setting is a community on Detroit's East Side, where according to the 2015 U.S. Census Bureau's American Community Survey, the per capita income is $\$ 15,611$ and the median household income is $\$ 25,980$ by census tract [70]. The East Side is among the poorer areas in a city in which $39.3 \%$ of residents live in poverty [6]. The community is predominantly African American and disproportionately affected by unemployment, with unemployment rates of $13.6 \%$ for AfricanAmerican adults of working age-over twice the $5.9 \%$ rate for white workers [53].

\section{Research Team}

Because of our participatory action research approach and the involvement of project participants as paper co-authors, some background about the co-authors will help contextualize the findings of this paper. We, the research team, consisted of four university researchers-whom we will collectively call the university team - and two community researchers. The university team was composed of two university professors and two graduate-student researchers. One of the professors has been investigating barriers to social mobility in Michigan for several years; the other has studied the interplay of digital technologies and socio-economic development for over a decade and has experience with both for-profit and nonprofit entrepreneurship. One of the graduate students is an HCI researcher who was raised in India; the other was raised in Detroit and has lived on the East Side. One of the two community researchers has lived in the city since the early 1970s; the other is a lifelong resident of Detroit. Both have held a variety of jobs - one as a factory inspector, optician, and teaching assistant; the other has held jobs in automobile 
manufacturing and food services. Both are active as leaders in local community-development efforts of the Eastside Community Network (ECN). Throughout the paper, we use the term community participants to refer to any community member who participated in at least one community meeting. This also includes the community researchers.

\section{Mentorship and Partnership}

To maximize ownership of the entrepreneurial venture by the community participants, the university team sought to have the community participants undertake as much as they could on their own, and to provide assistance only where it seemed needed. This overall policy extended not only to efforts to prepare for the tour, but also with respect to how the project itself was managed. Throughout, the community participants were encouraged to decide for themselves what next steps were required, to brainstorm ideas for preparation, and to execute any required actions. Wherever community participants seemed unable to make progress, or where discussion seemed to benefit from unconsidered expertise, the university team suggested next steps, offered guidance, or took action as necessary. Three exceptions were made to this overall policy. Two of them allowed the research to focus on hidden requirements for entrepreneurship: First, the university team planned and developed all technology requirements for the project, including online marketing and payment platforms. Second, the university team underwrote advance costs for the project, though these were subtracted from gross revenue before net proceeds were paid to participants. Finally, mentoring the community participants on website development or fundraising would have required significant efforts that went beyond the goals of the research.

\section{Formal Interviews}

Approximately 6 weeks after the pilot tour was completed, the university team conducted formal semi-structured interviews with the community researchers in their capacity as project participants. The interviews were conducted separately with each community researcher and lasted about 2 hours each. All interviews were audio-recorded and professionally transcribed. The interview protocol included questions about expectations of the project, efforts toward the tour, support received, lessons learned, challenges encountered, relationship with the university team, technology used, interest in continuing with future tours, and other issues that arose throughout the duration of the project.

\section{Tour Evaluations}

Upon completion of each tour, all attendees received a questionnaire to help evaluate and provide feedback about the tour. The questionnaire included demographics (e.g., age, gender, current city), their perceptions of the city before the tour and after the tour, feedback about the tour content, the tour guides, if they would recommend the tour to others, and general suggestions for improving the tour.

\section{Analysis}

We used these formal interviews as the basis of our initial analysis, which followed a contextual inquiry method [5].
Two members of the university team separately coded all formal interview transcripts and field notes. The two university team members looked over the codes multiple times to reach agreement and to resolve discrepancies; they then created an affinity diagram of the coded notes and utterances, and clustered them by common themes. The two university team members reconciled codes with similar semantics. The university team as a whole identified increasingly broader categories of expressed needs and requirements for a successful launch of the enterprise until consensus was met. The themes that emerged correspond to the subheadings in the Findings section. Once the high-level themes were identified, the university researchers scanned participant observations and comments from tour evaluations for additional supporting evidence of each theme.

\section{Timeline}

To provide a sense for the activities undertaken, we provide a very brief chronological summary of key events. All events occurred in the year $2016^{3}$ and all names, except Minnie and Delores', are pseudonyms: Feb. 10: Informational meeting held. Three community participants (Paulina, Delores, Moude) attended. April 25: Community participants provided their tour ideas. A new attendee, Minnie, a community member who ran her own neighborhood tour, described her tour, and noted her technical needs, which the university team helped with. Community participants proposed walking tours; Moude left because of concerns of the tours' physical requirements. June 28: Participants agreed to follow Minnie's tour format of two back-to-back 2-hour bus tours. A new community participant, Martha, suggested a "bootleggers' tour." Participants rallied around her idea and abandoned other tour ideas. Oct. 22: Pilot tours: Community researchers, Minnie and Delores conduct two back-to-back tours. Team distributed feedback surveys.

\section{TOUR OUTCOMES}

We achieved our goal to launch a neighborhood tour that was operationally profitable and that was largely conceived, planned, and executed by community participants.

Although we considered several themes throughout the project - a ceramics factory, Belle Isle (an island park with cultural attractions), underground railroad, local churches, street art-we ultimately settled on a bootlegger's tour that visited several sites of interest to Detroit's Prohibition Era history, including a point on the Detroit River where alcohol smugglers crossed from Canada, a church whose expansion smugglers paid for to store alcohol, a house that served as a speakeasy with an underground tunnel to a neighboring house, and a bar adjacent to a creek known for bootlegging traffic.

We conducted two pilot tours about 10 months after the start of the project, each led by the two community researchers. A total of 44 customers took the tours (including the four members of the university team), filling the 24-passenger bus to nearcapacity on each tour. Customers paid between $\$ 20$ and $\$ 40$ a ticket, based on variable discounts offered to students and Detroit residents. Seven people paid the full $\$ 40$ ticket price. The tours grossed $\$ 1,040$ from ticket sales, which came to a

\footnotetext{
${ }^{3}$ See supplementary material for a detailed timeline.
} 
net profit of $\$ 638$ after subtracting the bus rental costs, tour snacks for customers, and payment portal fees. These figures do not include the total costs of tour preparation, which were contributed in kind by the university team and community participants-labor, meeting space, transportation to meetings, minor printing costs, information technology (IT) costs, and light snacks provided at meetings. However, because most of those costs were one-time start-up expenditures, we believe that the enterprise could comfortably break even as the tours are repeated.

About three quarters of the tour customers were drawn from communities that the project teams had at least some loose affiliation with: family and friends of the project team, and faculty and students from the university team's campus. However, the remaining one quarter of the customers were either complete strangers to the project team (they had seen flyers or received email announcements), or at least two degrees of separation away from the project team (they had received forwarded email announcements about the tour). This composition suggests that improved marketing is necessary if the enterprise were to continue, but also that there is latent demand for tours of this kind, which supports the results of our early investigation of this concept.

Both written and verbal comments from tour evaluation surveys suggest that the tours were a success. Although we believe the neighborhood tour launched successfully, with the vast majority of our initial objectives met, a number of issues preclude us from claiming a total victory. Most salient, at least for the university team, is how few community participants we were able to see through to the pilot despite the time spent in team meetings. Only the two community researchers remained until the end. (More about this point is noted in the subsection on personal challenges.) Another issue is that as much as we aimed for community participant ownership of the enterprise, there remain residual dependencies on the university team. These include operation of the tour website and payment portal, an organizational structure, and a means for financing continued operation. These are significant deficiencies, which we will continue to address separate from our research goals. Finally, though we are reasonably confident that the bootleggers' tour can operate profitably, revenues from the pilot tours alone far from recovered the total start-up costs of the enterprise. Without continued operation, the total cost of just the community participants' labor so far would not be recuperated, to say nothing of university team labor.

These caveats notwithstanding, we proceed to our research findings on the basis of a successful entrepreneurial launch.

\section{HIDDEN AND UNDERESTIMATED REQUIREMENTS}

This section details our analytical findings. Table 1 provides a summary of our findings and identifies those hidden and underestimated (predominately non-technical) requirements needed for a successful entrepreneurial endeavor in a lean economy. In developing this table, we categorized all requirements identified into those categories named in prior work, such as human and social capital [47], and added two requirement categories: business development and incubation, and infrastructure and institutional support. Funding was a known entrepreneurial requirement [24]. However, besides the financial capital for launch, the results of the tour did not uncover any additional funding requirements. For completeness, we also discuss in this section the technical requirements for the venture and conclude with a discussion of personal challenges that community participants faced. We provide more textual content on the findings that were most salient.

\section{Human and Social Capital}

The essence of our findings is that there are many critical human factors to a successful small-business launch. These factors are often clumped together as "intangibles" in the research literature on entrepreneurship, but they emerged as the most salient themes in our study. We deemed these factors human capital and individual capacities, per Table 1, and found it unlikely in our context for technology to address these requirements.

Because many of these factors were retroactively viewed as lessons learned or benefits gained from participation, the discussion that follows blends entrepreneurial requirements and benefits. We also focus the discussion on the community researchers, who stayed with the project until the completion of the pilot.

\section{Community Participant Motivation (A.10)}

Entrepreneurs repeatedly cite passion and motivation as a key to success [39], and research has confirmed that motivationboth as the desire to be an entrepreneur, and as the personal characteristics that cause one to persevere in spite of challenges-is strongly correlated with entrepreneurial success $[4,64]$. We believe our community participants started the project with considerable motivation of their own. At a basic level, most of the participants kept coming back to the planning meetings even though there were no tangible short-term rewards and any potential pay-off was distant. Several community participants also had difficulty arranging transportation to attend meetings but still returned multiple times.

A closer examination of their motivations suggests several factors. The one most frequently expressed was a desire to share a different side of the city from the one portrayed in mass media, which tends to emphasize its economic problems. Delores believed the tours would be a way for her to share her positive childhood experiences. After the tour, she reiterated this point: "[The tour] was very good for me because it gave me a time to express how I really feel about growing up here. I think I had a fantastic childhood... [the city] was a wonderful place to be... and that was something that I felt good about being able to talk about." Minnie said that she wanted to "do something better for our community. That was my main purpose of doing this here." She was also hoping that a federation of community block clubs that she led would gain more visibility in the process. Moude often raised issues of racial injustice in the history of Detroit. Per Dombrowski et al., designing for recognition means identifying and addressing past injustices [19] and this was reflected in our participants' motivation. This motivation stemmed from our participants' ability to use the tours to share their positive stories about their community and offset the media's often negative portrayal of their community. 


\begin{tabular}{|c|c|c|c|c|c|c|}
\hline & \multirow[t]{2}{*}{ Entrepreneurship Requirements } & \multicolumn{3}{|c|}{$\begin{array}{l}\text { Supplying } \\
\text { Entity in } \\
\text { Tour } \\
\text { Enterprise }\end{array}$} & \multirow[t]{2}{*}{ Addressable through Technology or Technology Mediation? } & \multirow[t]{2}{*}{ Technological Opportunities } \\
\hline & & CR & $C P$ & & & \\
\hline \multirow{10}{*}{$\begin{array}{c}\text { A) Human } \\
\text { Capital/Indivi- } \\
\text { dual Traits and } \\
\text { Capacities }\end{array}$} & A.1) Self-efficacy & & & & X Unlikely; partially, with established trust (Crowdfunding sites [30]) & \multirow{10}{*}{$\begin{array}{l}\text { Learning tools to support social, research, and } \\
\text { entrepreneurial skills. There are also opportunities } \\
\text { for tools to foster public speaking; however, this } \\
\text { requires a self-efficacy component as a critical first } \\
\text { step. In addition, a mechanism to increase } \\
\text { awareness of the tools available to address these } \\
\text { needs is also a requirement. At this time, it is } \\
\text { unlikely that a tool could help to foster cultural } \\
\text { capital or address the personal health issues that } \\
\text { arose unexpectedly (at least not in this context). }\end{array}$} \\
\hline & A.2) Social Skills & & $\mathrm{x}$ & & Unlikely & \\
\hline & $\begin{array}{l}\text { A.3) Research Skills and } \\
\text { Entrepreneurial Knowledge }\end{array}$ & & $\mathrm{x}$ & & $\begin{array}{l}\text { Partially; (YouTube, blogs) (see [18] and [26] for contextual } \\
\text { barriers) }\end{array}$ & \\
\hline & A.4) Cultural capital & & $\mathrm{x}$ & & Unlikely in in the context of this study (see [32]) & \\
\hline & A.5) Public speaking ability & & $\mathrm{x}$ & & Unlikely & \\
\hline & A.6) Personal Health & & $\mathrm{x}$ & & Unlikely & \\
\hline & A.7) Awareness of tech. resources & & & & X Unlikely; requires bootstrapping [16] & \\
\hline & A.8) Ability to see opportunities & & $x$ & & X Partially (Quirky.com, a community-led invention platform) & \\
\hline & A.9) Perseverance & $\mathrm{x}$ & & & Partially (StickK.com, to stick to commitments and goals) & \\
\hline & A.10) Motivation & & $\mathrm{x}$ & & Partially (Fitbit, Mint, a financial application) & \\
\hline \multirow[b]{3}{*}{$\begin{array}{l}\text { B) Social } \\
\text { Capital }\end{array}$} & B.1) Social networks and support & & $\mathrm{x}$ & $\mathrm{x}$ & Unlikely in in the context of this study $[11,14]$ & \multirow{3}{*}{$\begin{array}{l}\text { While there is existing support to developing social } \\
\text { capital opportunities, there are none to provide } \\
\text { emotional support. }\end{array}$} \\
\hline & B.2) Emotional and moral support & & $\mathrm{x}$ & & Partially (technology tools to communicate with family/friends) & \\
\hline & B.3) Trust within project team & & $\mathrm{x}$ & & $\begin{array}{l}\text { Partially (some sharing economy platforms such as Airbnb and } \\
\text { Uber eliminate the need for institutional support; however, issues } \\
\text { of critical mass exist in certain contexts }([16,17])\end{array}$ & \\
\hline \multirow{6}{*}{$\begin{array}{l}\text { C) Business } \\
\text { Development } \\
\text { / Incubation }\end{array}$} & C.1) Pricing & & & & X Unlikely & \multirow{6}{*}{$\begin{array}{l}\text { Several opportunities for business development } \\
\text { and incubation exist in this context; pricing is a } \\
\text { challenge --especially among individuals who may } \\
\text { have low self-efficacy and not know their true } \\
\text { worth or value. }\end{array}$} \\
\hline & C.2) Marketing materials & & & $\mathrm{x}$ & X Unlikely for content; likely for distribution (Facebook, email) & \\
\hline & C.3) Project management & & & & X Unlikely & \\
\hline & C.4) Competitive analysis & & & & X Likely; online resources & \\
\hline & C.5) Structure of Tour & & $\mathrm{x}$ & & Likely; online resources & \\
\hline & C.6) Development of Tour Script & & $\mathrm{x}$ & & X Likely; via templates & \\
\hline \multirow{3}{*}{$\begin{array}{l}\text { D) } \\
\text { Infrastructure } \\
\text { / Institutional } \\
\text { Support }\end{array}$} & D.1) Meeting place & & & $x$ & $\begin{array}{l}\text { Unlikely for physical meetings (Liquidspace, meeting spaces for } \\
\text { professionals); Likely for virtual meetings }\end{array}$ & \multirow{3}{*}{$\begin{array}{l}\text { While support for physical meeting spaces is an } \\
\text { open opportunity and challenge, providing } \\
\text { additional characteristics that are needed for an } \\
\text { enterprise to thrive in the environment is a difficult } \\
\text { challenge for technology to address and perhaps } \\
\text { impossible at this time. }\end{array}$} \\
\hline & D.2) Payment website & & & & $\begin{array}{l}\text { Likely; EventBrite used though not perfect for this context } \\
([16,17])\end{array}$ & \\
\hline & D.3) Tour website & & & & X Likely, Wordpress and Facebook used for this context & \\
\hline E) Funding & & & & & X Partially; (see Crowdfunding sites [26,35], Kiva, etc.) & $\begin{array}{l}\text { Funding support exists; however, self-efficacy and } \\
\text { awareness are required. }\end{array}$ \\
\hline
\end{tabular}

Table 1. There are many requirements to succeed at even a simple enterprise, and most cannot be easily met or facilitated with technology. The leftmost column indicates the knowledge, abilities, and resources that are required to succeed with the enterprise. (Letters in parentheses refer to qualities described in the text.) The middle column notes the entities that supplied the requirement at left; $\mathrm{CP}$ - community participants, $\mathrm{CR}$ - community researchers, UT - university team, P-community partner. Note that community participants either came in with or supplied these requirements. The rightmost columns indicate (1) our estimate-likely, partially, or unlikely_of the requirement being addressable by a technology or technology mediation and (2) technological opportunities. (Relevant references include $[11,16,17,18,26,30,32,35]$.)

Another motivator was the potential for additional income. Although the community researchers did not see the financial benefits as the main reason for participating, we did appreciate the income. When we received the profits from the tour, it was a very pleasant surprise. The experience of the project itself was its own reward, but to have received some income from the first tour was gratifying. For the other community participants, the initial flyers advertising the project emphasized the project's potential to provide supplemental income, so that was undoubtedly the initial draw. The participants expressed their interest in income at various meetings. Paulina mentioned that she could use additional income, and Moude made references to wanting to buy a car. Minnie noted the difficulty of making a profit from her own tour: "Instead of me helping my [non-profit] organization, I was spending what my organization had and we was coming out even. I wasn't making anything."

Finally, the community researchers were generally interested in activities to support community development. Delores was on the board of the project's non-profit partner and president of a community block club. Minnie was head of a federation of community block clubs and engaged in a number of community activities. We felt that by helping to launch a viable business, we could eventually increase the net income coming into our community and create more jobs. Of course motivation alone is not sufficient for entrepreneurship, and we next discuss many success requirements that we encountered.

\section{Self-Efficacy (A.1)}

Studies consistently note that self-efficacy - a person's confidence in his or her ability to accomplish a task-plays a large role in entrepreneurship [8, 10, 72], and both Minnie and Delores noted that project involvement had dramatic impacts on how they saw themselves, both directly and reflected in how their communities saw them. They both believed that the tour experience boosted their confidence and sense of selfworth. For example, Minnie noted that she now could give her own tour (for which she previously hired a paid guide). Both participants reported feeling more outgoing, having an increased sense of independence, and overcoming fears of public speaking and trying new things. Participants expressed feeling more enlightened.

Some of these gains in self-efficacy also came from deliberate efforts on the part of the university team to offer moral support through basic acknowledgment, validation, and encouraging feedback. Delores recalls,

[The university team member] said, "Do an outline of [the itinerary]," and I did, and you know, he never said, this is wrong, or this is right, he just said, "Okay, well we're going to take this, and we're going to set it up, and critique it," and what have you. As he did that, I learned how to really get this business going, how to set it up. 
This kind of encouragement-delivered in person in face-toface meetings-was repeatedly and insistently cited as a critical part of the community researchers' sustained participation in the year-long planning process.

Finally, Minnie and Delores both cited their families as an area of social support and stated that their family members gave them encouragement throughout the experience. Delores says, "Oh, I don't know how to say it, other than it made me feel like I can do some of the things my son tells me all the time that I can do... that I can do anything." We discuss social networks in detail next, however, we wish to highlight that these results show how social support (B.1) in addition to the tour experience, led to improved self-efficacy.

\section{Social Capital and Social Networks (B, B.1)}

Social networks were beneficial in obtaining access to tour stops, reaching potential customers, and obtaining a tour bus. The community partners and university researchers reached out to and visited a local bar to accommodate the tours. The bar owner, who also offered creek tours, happily accommodated our tours as well. As stated earlier, a large majority of the tour customers had social or familial ties with members of the project team. The benefits from our social ties resulted in increased social capital.

In terms of obtaining the tour bus, the university team sought quotes from three different operators, two of which had relationships with community participants and one that the university researchers found online. The online company, which we contacted without an introduction via email, responded quickly but then failed to follow up as university researchers emailed additional questions. The rental company we ultimately used was the same one that Delores used in a previous tour. Discussions with this company went smoothly, piggybacking on the prior relationship.

\section{Research Skills and Entrepreneurial Knowledge (A.3)}

The community researchers also noted that they gained a range of concrete new knowledge and skills that were critical to the tour. Both reported learning new information about Prohibition Era Detroit as a prerequisite for serving as tour guides.

The community researchers also indicated that they learned more about the basics of a small business. For example, one of the ongoing discussions at planning meetings was how the tour should be priced. Minnie's own tour started with tickets at $\$ 15$, but she found that this price was not enough to turn a profit. The university team recommended a scheme with price discrimination to maximize revenue, with $\$ 40$ as the base price (C.1), with discounts offered for groups. Delores stated that through these discussions, she learned how to price a tour (C.1). Minnie and Delores also became more versed in marketing, as the project team collaborated to draft and distribute marketing materials through various mediums (C.2) including paper flyers, emails, websites, and social media. Both participants indicated that the experience also boosted their leadership skills, as they took on more responsibility for the pilot tour. Finally, Minnie and Delores mentioned benefiting from the university team participating in the ideation process, engaging with them as they came up with ideas and helping refine those ideas through careful evaluation (A.3).

Both Minnie and Delores also learned new digital skills. Delores went to local public libraries and befriended librarians who showed her how to find and use the library's physical resources as well as how to conduct online Google searches (A.3, A.7), which she then performed multiple times to flesh out the tour script.

Much of the entrepreneurial knowledge and skills were conveyed by the university team to the community participants (B.1). Minnie noted, "[At first,] it seemed like it was just over my head. See, you all brought things down to earth for me, and it was very easy for me to learn what to do." However, some of the knowledge was transferred between community participants, as well. For example, Minnie's own tour provided the format for the bootleggers' tour as a 2-hour bus tour (A.3). Until Minnie joined the project team, the others were considering foot tours or tours given in private cars to small groups. Also, the idea of the bootleggers' tour itself came from Martha, who, though she dropped out prior to the pilot, offered the one tour concept that the university team thought was most likely to succeed, the one the whole project team rallied around.

\section{Cultural Capital (A.4)}

One subtle requirement for the pilot's success was a certain kind of cultural capital having to do with what customers want and how they value it. Bourdieu's notion of cultural capital includes knowledge — often differentially distributed by social group - that allows people to navigate their socio-economic environments to various degrees [7].

Minnie and Delores both reported that the tour altered their view of how others perceived them and their community. Before the tour, neither could fathom tour-goers paying $\$ 40$ for a ticket (C.1), or that people 50 miles away would be interested in attending a tour of a lesser-known neighborhood of Detroit, much less hearing the personal stories of local residents. Multiple times during tour planning, the university team tried to convince the community researchers of the very possibility of these things, but Minnie and Delores remained unconvinced until the tour took place. The cultural capital of potential customer demand was a critical part of the success of the tour, and one that the university team had to gently impose.

The fact that a range of customers attended also gave the community researchers a sense of personal validation. They saw that other people did want to hear their personal stories as well as the less-known history of the city that Minnie and Delores lived in. This validation also fed back into their selfefficacy (A.1) for future tours.

\section{Business Development / Incubation (C)}

Business development and incubation included specific ideas and concepts that were developed for the tour itself. We separately categorized any abilities required to provide these ideas and concepts into "human or social capital." Therefore, many of the business development and incubation requirements have been previously discussed. For example, the university team facilitated team meetings and pricing, and provided a competitive analysis and the flyer for marketing (C.1-C.4). The 
community participants managed the structure of the tour and we all supported the tour script's development (C.5, C.6).

\section{Infrastructure and Institutional Support (D)}

Infrastructure and institutional support included any physical or virtual artifacts that were required for the business to operate. These requirements were primarily met by the Eastside Community Network, the local community-based organization that the researchers partnered with. The organization provided the team with meeting space to facilitate group meeting, allowed the team to use the facility as the tour start/stop destination, and also allowed tour attendees to park in a gateenclosed facility free of charge on the day of the tours (D.1). Finally, the organization helped to promote the tours and the staff members continuously expressed their willingness to help. As mentioned, the university team facilitated the payment and tour website (D.2, D.3).

\section{Technical Requirements for Success}

In this section, we provide an overview of how technology was used in the tour. We then discuss the requirements we identified as unlikely to be addressable or mediated via technology. As mentioned earlier, the university team planned and developed all technical requirements for the project (C.4, C.6, D.2, D.3). The community research team used technology at a minimum (B.1, C.6).

\section{Requirements Addressed via Technology}

The university team, serving primarily in this case as an intermediary [62], selected a payment platform and created a website for the tour to aid in online marketing. Without this system, the team would not have been able to sell tickets in a centralized way and gauge tour group size in advance. However, this system did not adequately meet the needs of the community research team (D.2). For example, the team needed the platform to manage discounted rates, accept cash payments, and account for payments received on the day of the tour. While the selected platform accepted coupon codes for discounted rates, cash-paying customers as well as those who purchased tickets on the day of the tour had to be managed outside the context of the platform. The team coordinated these exchanges outside the platform.

The community research team leveraged technology to search for research content for the tour and often did so at the local library. All team members relied on technology tools to market the tours using email and social media to advertise the event. Advertising, however, was largely done among people with whom the team members had regular contact-family, friends, and colleagues at our respective organizations. Aside from these efforts, the role of technology was minimal.

Table 1 identifies areas where technology could potentially be used to support micro entrepreneurship in lean contexts. For example, the use of technology to recognize business opportunities or to support entrepreneurs in maintaining their goals (A.8, A.9), and the use of crowdfunding sites to fund tours (E) [26, 34]. However, as noted in Related Work, these tools have not been shown to effectively work in lean environments. Per our results and given the results of prior HCI and CSCW literature $[16,18,17,14,15]$, it would be very difficult for technology to address many of the human, social, and cultural capital requirements outlined in Table 1. Many of these requirements rely on a level of trust (B.3) that must be developed over time (e.g., forming social networks).

From a business development and incubation perspective (C), some sharing economy platforms such as Uber and Lyft provide pricing details on behalf of the micro entrepreneur. However, very few sharing economy, or other technological platforms provide support for setting price-points for individuals. Similarly, it is unclear whether project management tools could facilitate the development of the ideas and concepts required for the tour. Finally, as discussed next, very few forms of technology are capable of predicting, let alone supporting, some of the personal challenges (A.6, B.2) encountered by community participants.

\section{Personal Challenges (A.6)}

Most of the community participants experienced a range of personal challenges during the span of the project, which presented additional obstacles to overcome. Others caused participants to leave the project before the final tour.

The most severe challenges were deaths in the family that two of the community participants experienced, with one of them seeing four deaths within 3 months and another death leading to one of the participants leaving the program to mourn. The other participant was Delores, who missed a couple of meetings but continued to participate through the end in a testament to her perseverance.

Personal health and other issues also arose (A.6). One community participant dropped out in the middle of the project in part because she did not feel up to the physical requirements of giving a walking tour. Occasionally, personal issues arose, whose nature we did not always understand. One of our community participants contributed vocally and enthusiastically for several meetings, but gradually began withdrawing. She cited several things: busyness with other activities, a wish to avoid appearing on the website, a desire to avoid public speaking (as a tour guide), discomfort with another member of the team. We accommodated each of her explicit wishes, but ultimately our outreach was insufficient, and she left the project.

Finally, some participants had problems with transportation. Although all of the community participants lived within three miles of the meeting site, some found it difficult to travel to meetings. One participant who left the project midway did not own a car and depended on friends and relatives to drive her. Another participant used a bicycle for transportation, which limited her participation in bad weather.

We mention these issues not because of their uniquenessthey are universal experiences-but because the university team took note of their frequency and salience. For the university team, many of the issues were perceived as severe life challenges that would typically disrupt professional activity. Responses from the community participants varied: Sometimes, the challenge led to an end to their participation. More often, however, community participants met the challenges with grace and resilience. We believe that the frequency 
of these life challenges is a symptom of larger structural inequities that systematically disrupt entrepreneurship efforts in lean settings, but in ways that are easy to dismiss or neglect as one-off events.

\section{DISCUSSION}

In a world immersed in digital technology, and in a research community- HCI - that is tied to technology even as it emphasizes the "socio" in socio-technical systems, it is difficult to convey the profound human requirements of certain activities.

We begin with the fact that a fast-rising tide of Silicon Valley platforms and rhetoric has nevertheless failed to lift all boats. Given the energy and immense resources applied to the effort, the question is why: Why is it so difficult for highly successful technology companies that claim a desire to cause positive change to boost lean economies?

In our project, a university team supplied all of the technological and financial needs to an entrepreneurial venture in a lean-economy U.S. city, specifically so that we could examine the social requirements uncomplicated by questions of technical design and implementation. What we encountered was Ackerman's socio-technical gap [1] widened and deepened into a chasm that we suspect cannot be easily bridged from the technology side. While Ackerman articulated theoretical reasons for this gap in white-collar contexts, our results show that in lean-economy contexts, the reasons are multiplied, contributing to a bigger gap. As others have found, some contexts will require intermediation $[62,69]$, direct and genuine human effort, attention, and interaction for the foreseeable future. ${ }^{4}$

We deepen this finding by identifying motivation and selfefficacy as key factors that technology cannot easily bridge. Ackerman was concerned with traditional white-collar contexts, where, for example, knowledge workers have nuanced ideas of information sharing that brittle technology cannot match. What we found is more fundamental, involving multiple levels of trust and multiple forms of direct human interaction that afford little opportunity for technological streamlining. We argue that fostering novice entrepreneurship requires four critical components, at least two of which are nearly impossible to facilitate with technology. Distilling the root causes of the many individual requirements noted in the previous section, these four components are: (1) buildup of entrepreneurial self-efficacy, (2) trust between the entrepreneur and supporters, (3) marshalling of external expertise and support, and (4) transfer of knowledge and skill to the entrepreneur. At first glance, some if not all of these components seem amenable to technological replacement or facilitation. Knowledge of all kinds is readily available online. Calls for external support can be made through crowdfunding. And, some social media interactions are linked to increased selfefficacy [13]. But, a closer look reveals that these conclusions cannot be glibly applied to lean contexts.

\section{Build-up of Entrepreneurial Self-efficacy}

As discussed in the Related Work section, self-efficacy appears prominently in the literature on general entrepreneurship, and

\footnotetext{
${ }^{4}$ This may change in a potential future of, for example, humanoid robots that are indistinguishable from human beings.
}

with good reason. It could be argued that entrepreneurial self-efficacy is a sufficient condition for success because with it, an entrepreneur would persevere and do whatever it takes to succeed-a trait that both researchers and entrepreneurs repeatedly highlight as a condition for success $[47,66,72]$. Indeed, Bandura's claims for self-efficacy are that it not only provides faith in one's ability to accomplish a task, but much of the motivation to complete it, as well [3].

Accordingly, the community researchers indicated that boosts to self-efficacy was the most salient result of the projectgreater self-efficacy about public speaking, greater selfefficacy in developing a tour itinerary and script, greater selfefficacy about planning and execution, and greater self-efficacy in running an enterprise. Were there some way to generate all of these forms of self-efficacy technologically, we could stop and declare the socio-technical gap closed. Instead, we found that in this context, increasing self-efficacy required trust and ongoing human interaction.

\section{Trust between Entrepreneur and Supporters}

Trust between the community participants and the university team was absolutely essential for many of our outcomes, including the nurturing of self-efficacy. Little of the encouragement or coaching that the university team provided would have been taken to heart without trust. While we acknowledge existing systems that can increase self-efficacy (see Table 1, Technological Opportunities), in our context, technology must support the development of trust between stakeholders first. So, a key question is whether this required trust can be facilitated by technology.

It seems likely that at least some of the meetings could have been conducted by phone or over video teleconferencing. But as others have found, remote collaboration usually requires a framework for trust that precedes the technology $[29,56,60]$. And, while trust between strangers can be developed on virtual platforms under certain conditions [73], those conditions are the very ones lacking in many lean communities, where the default between strangers is mistrust and suspicion [23, 28, 43]. The university team experienced this skepticism at our first two meetings, when at least three community participants asked us versions of the question, "What's in it for you?" This was in spite of the trust the university team inherited from our non-profit partner [49].

Ultimately, the context allowed no substitute to building up trust except through some in-person interactions; once that trust was built, more and more of our communications could move to phone and email. Indeed, Minnie and Delores noted that their trust in the university team increased over time because of the simple fact that the university team was willing to make the 1-hour trip to the meetings. This signaled that the university team cared about the community participants and valued the project. Conversely, the university team had reasons to trust the community participants when they came back to each project meeting - it signaled their commitment to the project despite doubts that were expressed during the meetings. As we discuss the other requirements next, trust appears and re-appears as a crucial element. What we found is that any 
technology that aims to foster trust must be designed for engagement with multiple users [62], a technological implication suggested by Sambasivan et al. in the context of intermediated technology in Indian urban slums. While our environment differs from that of [62], perhaps the technological challenges and solutions are similar.

\section{Marshalling of External Support}

Much of entrepreneurship involves the coordination of a range of support. In our case, we needed space to meet, a rental bus, tour-giving knowledge, help marketing the tour, agreements with owners of visited sites, and so on, with many of these resources scattered across multiple entities. Many of these resources are readily available online in wealthier contexts, but on Detroit's East Side this depended on chains of personal trust and in-person meetings. Something as straightforward as renting a bus, for example, required university researchers to go through the community participants' existing networks.

Of the four distilled requirements, we suspect that marshalling of support is the one most conducive to technological facilitation, but because of the unique nature of enterprises and their local contexts, we suspect that they will still experience Ackerman's original conception of the socio-technical gap.

\section{Transfers of Knowledge and Skill to the Entrepreneur}

Entrepreneurial knowledge seems eminently conveyable through technology. There are countless blogs, YouTube videos, and increasingly, free online courses that claim to teach entrepreneurship. But while all community participants had smartphones and some degree of data access, none had received help online for entrepreneurship. The main obstacle to successful knowledge transfer was not the provision of information, per se, but the social engagement required to absorb it. And again, knowledge transfer requires trust. There is little reason to trust the random advice available online unless it is recommended by people or organizations one trusts. Second, people need to be aware that relevant information exists in the first place before they will seek it out, and awareness, too, must come from trusted sources. Yet another requirement is repeat exposure. Most people do not digest information in one dose or learn a skill at one sitting; knowledge requires repetition to absorb.

Finally, in some cases, lessons must be imposed, with complex ethical considerations taken into account. The community researchers realized that customers would pay $\$ 40$ for the tour only after the university team sold tickets online at that price; the university team made the decision to go ahead based on a careful weighing of benefits and risks, something they would not have felt comfortable doing without a strong platform of trust. It is not at all clear how any of these specific instances can be replaced with technology.

None of the four distilled requirements demands rare expertise or Herculean effort. Yet, there are deep reasons for their irreducibility to technology. Perhaps most challenging is that in order to overcome the low baseline of stranger-to-stranger trust that is common to many micro entrepreneurs in lean environments, stakeholders must invest in social interactions that are inescapably tied to human effort — not to the effort's outcome, but to the meta-message conveyed by the expenditure of effort. A useful analogy is the handwritten thank-you note, whose value lies in the slow human effort required to manually write it. A tech-facilitated thank-you requires less effort, which is exactly why it has less value. Similarly, had we substituted the physical meetings with teleconferences, less trust would have developed, likely taking away from the collaborative relationship required for the transfer of entrepreneurial skills.

\section{STUDY LIMITATIONS AND FUTURE WORK}

This research has several limitations. First, we began with five tour guides; however, only two successfully conducted the tour-these are very small numbers from which to draw conclusions. A related issue is that in the absence of a "control" condition, it is difficult to say what could have happened if we had run the project another way. For the sake of a close-up view of the socio-technical gap, we opted for a very in-depth, participatory approach, but a larger-scale study is required for greater external validity.

With respect to the viability of the enterprise, there are additional issues. First, about a quarter of those attending the final tours were unaffiliated with the community organization or university. Therefore, it is possible that future tours might not be as successful and that our positive survey outcomes reflected attendee bias. Finally, the community tour project is not yet sustainable. Our aim is to address these shortcomings in the future. Going forward, the university research team also plans to continue facilitating these tours until there is critical mass to reach a series of tours that are sustainable.

\section{CONCLUSION}

This study (1) confirmed past technical requirements such as the need for tools to obtain financial and social capital; (2) identified new technical requirements such as the need for tools to support incubation (e.g., set price points) and support human capital (e.g., instill a sense of independence, foster self-efficacy). This study additionally (3) uncovered hidden, non-technical requirements such as the need for support during personal challenges; social support and direct interaction to build trust for entrepreneurial success among novice entrepreneurs in lean economies.

We found issues around trust and motivation to be particularly challenging for technology to address, at least for the foreseeable future. And while dramatic new technologies-such as robots indistinguishable from people - might prompt a reassessment, our conclusion for the moment is that supporting people in lean economies toward entrepreneurship and other forms of social-economic growth requires resources applied toward human interventions, rather than the pursuit of tempting technological mirages. These results deepen our understanding of Ackerman's social-technical gap, and contribute implications for both civic technologists and policy-makers hoping to support entrepreneurship in lean economies.

\section{ACKNOWLEDGEMENTS}

We would like to thank the Eastside Community Network, our community participants, Suzanne Cleague, and Orlando Bailey for their contributions to this work. This work was supported by the NSF EAGER award IIS-1665049. 


\section{REFERENCES}

1. Mark S Ackerman. 2000. The intellectual challenge of CSCW: the gap between social requirements and technical feasibility. Human-computer interaction 15, 2 (2000), 179-203.

2. Peter Bailis, Tawanna Dillahunt, Stefanie Mueller, and Patrick Baudisch. 2017. Research for Practice: Technology for Underserved Communities; Personal Fabrication. Commun. ACM 60, 10 (Sept. 2017), 46-49. DOI:http://dx.doi.org/10.1145/3080188

3. Albert Bandura. 1977. Self-efficacy: toward a unifying theory of behavioral change. Psychological review 84,2 (1977), 191.

4. J. Robert Baum, Edwin A Locke, and Ken G Smith. 2001. A multidimensional model of venture growth. Academy of management journal 44, 2 (2001), 292-303.

5. Hugh Beyer and Karen Holtzblatt. 1998. Contextual Design: Defining Customer-centered Systems. Morgan Kaufmann Publishers Inc., San Francisco, CA, USA

6. Karen Bouffard. 2015. Census bureau: Detroit is poorest big city in U.S. (17 Sep. 2015). http://www . detroitnews . com/story/news/local/michigan/2015/09/16/ census-us-uninsured-drops-income-stagnates/32499231/

7. Pierre Bourdieu. 1984. Distinction: A social critique of the judgement of taste. Harvard Univ Pr.

8. Nancy G. Boyd and George S Vozikis. 1994. The influence of self-efficacy on the development of entrepreneurial intentions and actions. Entrepreneurship theory and practice 18 (1994), 63-63.

9. Colleen Casey. 2013. Critical Connections: The Importance of Community-Based Organizations and Social Capital to Credit Access for Low-Wealth Entrepreneurs. Urban Affairs Review (2013), 1078087413508915 .

10. Chao C. Chen, Patricia Gene Greene, and Ann Crick. 1998. Does entrepreneurial self-efficacy distinguish entrepreneurs from managers? Journal of business venturing 13, 4 (1998), 295-316.

11. Amit Chowdhry. 2016. Most Of Your Facebook Friends Are Not Your Real Friends, Says Study. (9 Sep. 2016). https: //www . forbes . com/sites/amitchowdhry/2016/01/30/ most-facebook-friends-are-not-your-real-friends \ - says-study

12. Andy Crabtree and Alan Chamberlain. 2014. Making It "Pay a Bit Better": Design Challenges for Micro Rural Enterprise. In Proceedings of the 17th ACM Conference on Computer Supported Cooperative Work \&\#38; Social Computing (CSCW '14). ACM, New York, NY, USA, 687-696. DOI :

http: //dx . doi . org/10.1145/2531602.2531618

13. David C. DeAndrea, Nicole B. Ellison, Robert LaRose, Charles Steinfield, and Andrew Fiore. 2012. Serious social media: On the use of social media for improving students' adjustment to college. The Internet and higher education 15, 1 (2012), 15-23.

14. Tawanna R. Dillahunt. 2014. Fostering social capital in economically distressed communities. In Proceedings of the SIGCHI Conference on Human Factors in Computing Systems (CHI'14). ACM, New York, NY, USA, 531-540. DOI:http://dx.doi.org/10.1145/2556288.2557123

15. Tawanna R. Dillahunt, Nishan Bose, Suleman Diwan, and Asha Chen-Phang. 2016. Designing for Disadvantaged Job Seekers: Insights from Early Investigations. In Proceedings of the 2016 ACM Conference on Designing Interactive Systems (DIS '16). ACM, New York, NY, USA, 905-910. DOI : http: //dx . doi .org/10.1145/2901790.2901865

16. Tawanna R. Dillahunt, Vaishnav Kameswaran, Linfeng $\mathrm{Li}$, and Tanya Rosenblat. 2017. Uncovering the Values and Constraints of Real-time Ridesharing for Low-resource Populations. In Proceedings of the 2017 CHI Conference on Human Factors in Computing Systems (CHI '17). ACM, New York, NY, USA, 2757-2769. DOI : http : //dx . doi . org/10.1145/3025453.3025470

17. Tawanna R. Dillahunt and Amelia R. Malone. 2015. The Promise of the Sharing Economy Among Disadvantaged Communities. In Proceedings of the 33rd Annual ACM Conference on Human Factors in Computing Systems (CHI '15). ACM, New York, NY, USA, 2285-2294. DOI : http://dx.doi.org/10.1145/2702123.2702189

18. Tawanna R. Dillahunt, Sandy Ng, Michelle Fiesta, and Zengguang Wang. 2016. Do Massive Open Online Course Platforms Support Employability?. In Proceedings of the 19th ACM Conference on Computer-Supported Cooperative Work \& Social Computing (CSCW'16). ACM, New York, NY, USA, 233-244. DOI :

http://dx.doi .org/10.1145/2818048.2819924

19. Lynn Dombrowski, Ellie Harmon, and Sarah Fox. 2016. Social Justice-Oriented Interaction Design: Outlining Key Design Strategies and Commitments. In Proceedings of the 2016 ACM Conference on Designing Interactive Systems (DIS '16). ACM, New York, NY, USA, 656-671. DOI:http://dx.doi . org/10.1145/2901790.2901861

20. Benjamin G. Edelman, Michael Luca, and Dan Svirsky. 2016. Racial discrimination in the sharing economy: Evidence from a field experiment. (2016).

21. Babson Executive Education. 2016. Platforms: Where the Sharing Economy and Entrepreneurship Ecosystems Meet. (2016).

http: //www . babson. edu/executive-education/ thought-leadership/technology/Pages/ platforms-where-sharing-economy-and-entrepreneurship \ -ecosystems-meet.aspx 
22. Hamid Ekbia and Bonnie Nardi. 2016. Social Inequality and HCI: The View from Political Economy. In Proceedings of the 2016 CHI Conference on Human Factors in Computing Systems (CHI '16). ACM, New York, NY, USA, 4997-5002. DOI :

http: //dx . doi .org/10.1145/2858036.2858343

23. Karen Evans, Penny Fraser, and Sandra Walklate. 1996. Whom can you trust? The politics of 'grassing' on an inner city housing estate. The Sociological Review 44, 3 (1996), 361-380.

24. Casey J. Frid, David M Wyman, William B Gartner, and Diana H Hechavarria. 2016. Low-wealth entrepreneurs and access to external financing. International Journal of Entrepreneurial Behavior \& Research 22, 4 (2016), 531-555.

25. Yanbo Ge, Christopher R. Knittel, Don MacKenzie, and Stephen Zoepf. 2016. (Oct. 2016).

http://www.nber. org/papers/w22776.pdf

26. Elizabeth M. Gerber and Julie Hui. 2013. Crowdfunding: Motivations and Deterrents for Participation. ACM Trans. Comput.-Hum. Interact. 20, 6, Article 34 (Dec. 2013), 32 pages. DOI : http://dx . doi . org/10.1145/2530540

27. Mareike Glöss, Moira McGregor, and Barry Brown. 2016. Designing for Labour: Uber and the On-Demand Mobile Workforce. In Proceedings of the 2016 CHI Conference on Human Factors in Computing Systems (CHI '16). ACM, New York, NY, USA, 1632-1643. DOI : http: //dx . doi . org/10.1145/2858036.2858476

28. Robert Halpern. 1995. Rebuilding the inner city: A history of neighborhood initiatives to address poverty in the United States. Columbia University Press.

29. Charles Handy. 1995. Trust and the virtual organization. Harvard business review 73, 3 (1995), 40-51.

30. Emily Harburg, Julie Hui, Michael Greenberg, and Elizabeth M. Gerber. 2015. Understanding the Effects of Crowdfunding on Entrepreneurial Self-Efficacy. In Proceedings of the 18th ACM Conference on Computer Supported Cooperative Work \& Social Computing (CSCW '15). ACM, New York, NY, USA, 3-16. DOI : http://dx. doi . org/10.1145/2675133.2675142

31. Gillian R. Hayes. 2011. The Relationship of Action Research to Human-computer Interaction. ACM Trans. Comput.-Hum. Interact. 18, 3, Article 15 (Aug. 2011), 20 pages. DOI : http://dx. doi .org/10.1145/1993060.1993065

32. Joey Chiao-Yin Hsiao and Tawanna R. Dillahunt. 2017. People-Nearby Applications: How Newcomers Move Their Relationships Offline and Develop Social and Cultural Capital. In Proceedings of the 2017 ACM Conference on Computer Supported Cooperative Work and Social Computing (CSCW' 17). ACM, New York, NY, USA, 26-40. DOI :

http: //dx . doi . org/10.1145/2998181 . 2998280
33. Julie Hui. 2016. Online Help-Seeking in Communities of Novice Innovators. In Proceedings of the 2016 CHI Conference Extended Abstracts on Human Factors in Computing Systems (CHI EA '16). ACM, New York, NY, USA, 218-222. DOI :

http: //dx. doi . org/10.1145/2851581.2859018

34. Julie S. Hui and Elizabeth M. Gerber. 2017. Developing Makerspaces As Sites of Entrepreneurship. In Proceedings of the 2017 ACM Conference on Computer Supported Cooperative Work and Social Computing (CSCW '17). ACM, New York, NY, USA, 2023-2038. DOI: http://dx.doi . org/10.1145/2998181.2998264

35. Julie S. Hui, Elizabeth M. Gerber, and Darren Gergle. 2014a. Understanding and Leveraging Social Networks for Crowdfunding: Opportunities and Challenges. In Proceedings of the 2014 Conference on Designing Interactive Systems (DIS '14). ACM, New York, NY, USA, 677-680. DOI :

http://dx.doi .org/10.1145/2598510.2598539

36. Julie S. Hui, Michael D. Greenberg, and Elizabeth M. Gerber. 2014b. Understanding the role of community in crowdfunding work. In Proceedings of the 17th ACM conference on Computer supported cooperative work \& social computing. ACM, 62-74.

37. Margareta Hult and Sven-Åke Lennung. 1980. Towards a definition of action research: a note and bibliography. Journal of management studies 17, 2 (1980), 241-250.

38. Tapio Ikkala and Airi Lampinen. 2015. Monetizing network hospitality: Hospitality and sociability in the context of Airbnb. In Proceedings of the 18th ACM conference on computer supported cooperative work \& social computing. ACM, 1033-1044.

39. The Experts Journal Reports: Small Business. 2013. The Most Important Traits for Entrepreneurs. (20 Aug. 2013). https://tinyurl . com/k405vyq

40. Nicolas Kokkalis, Chengdiao Fan, Thomas Breier, and Michael S. Bernstein. 2017. Founder Center: Enabling Access to Collective Social Capital. In Proceedings of the 2017 ACM Conference on Computer Supported Cooperative Work and Social Computing (CSCW '17). ACM, New York, NY, USA, 2010-2022. DOI : http://dx. doi . org/10.1145/2998181.2998244

41. Kahliah Laney. 2013. Launching Low-Income Entrepreneurs. Center for an Urban Future (2013).

42. Luke Eric Lassiter. 2005. Collaborative Ethnography and Public Anthropology. Current Anthropology 46, 1 (2005), 83-106. DOI:http://dx.doi.org/10.1086/425658

43. Christopher A. Le Dantec and Sarah Fox. 2015. Strangers at the Gate: Gaining Access, Building Rapport, and Co-Constructing Community-Based Research. In Proceedings of the 18th ACM Conference on Computer Supported Cooperative Work \& Social Computing (CSCW '15). ACM, New York, NY, USA, 1348-1358. DOI : http://dx. doi . org/10. 1145/2675133.2675147 
44. Min Kyung Lee, Daniel Kusbit, Evan Metsky, and Laura Dabbish. 2015. Working with Machines: The Impact of Algorithmic and Data-Driven Management on Human Workers. In Proceedings of the 33rd Annual ACM Conference on Human Factors in Computing Systems (CHI '15). ACM, New York, NY, USA, 1603-1612. DOI : http://dx. doi . org/10.1145/2702123.2702548

45. Silvia Lindtner, Anna Greenspan, and David Li. 2015. Designed in Shenzhen: Shanzhai Manufacturing and Maker Entrepreneurs. In Proceedings of The Fifth Decennial Aarhus Conference on Critical Alternatives (AA '15). Aarhus University Press, 85-96. DOI : http://dx. doi.org/10.7146/aahcc.v1i1.21265

46. Michael Luca. 2017. Designing Online Marketplaces: Trust and Reputation Mechanisms. Innovation Policy and the Economy 17, 1 (2017), 77-93.

47. Gideon D. Markman and Robert A. Baron. 2003. Person-entrepreneurship fit: why some people are more successful as entrepreneurs than others. Human Resource Management Review 13, 2 (2003), 281 - 301. DOI : http://dx. doi . org/10.1016/S1053-4822 (03) 00018-4

48. Mokeira Masita-Mwangi, Nancy Mwakaba, and Jussi Impio. 2012. Taking Micro-enterprise Online: The Case of Kenyan Businesses. In CHI '12 Extended Abstracts on Human Factors in Computing Systems (CHI EA '12). ACM, New York, NY, USA, 367-382. DOI : http://dx.doi.org/10.1145/2212776.2212815

49. Bill McEvily, Vincenzo Perrone, and Akbar Zaheer. 2003. Trust as an organizing principle. Organization science 14, 1 (2003), 91-103.

50. Alice McIntyre. 2007. Participatory action research. Vol. 52. Sage Publications.

51. Michael Muller, Werner Geyer, Todd Soule, Steven Daniels, and Li-Te Cheng. 2013. Crowdfunding Inside the Enterprise: Employee-initiatives for Innovation and Collaboration. In Proceedings of the SIGCHI Conference on Human Factors in Computing Systems (CHI '13). ACM, New York, NY, USA, 503-512. DOI : http://dx. doi . org/10.1145/2470654.2470727

52. Mohamed Musthag and Deepak Ganesan. 2013. Labor Dynamics in a Mobile Micro-task Market. In Proceedings of the SIGCHI Conference on Human Factors in Computing Systems (CHI '13). ACM, New York, NY, USA, 641-650. DOI :

http://dx. doi . org/10.1145/2470654.2470745

53. JP Morgan Chase \& Co. New Skills at Work. 2015. Driving Opportunity in Detroit: Building a middle-skill workforce to strengthen economic recovery and expand the middle class. (Apr. 2015). https://www . jpmorganchase . com/corporate/Corporate-Responsibility/document/ 54841-jpmc-gap-detroit-aw3-final.pdf

54. Dayo Olopade. 2014. The bright continent: Breaking rules and making change in modern Africa. Houghton Mifflin Harcourt.
55. Peter Osalor. 2016. The impact of entrepreneurship on economic growth, Development. Vanguard (17 Oct. 2016). http: //www . vanguardngr . com/2016/10/ impact-entrepreneurship-economic-growth-development

56. Elinor Ostrom, James Walker, and Roy Gardner. 1992. Covenants with and without a Sword: Self-governance Is Possible. American political science Review 86, 02 (1992), 404-417.

57. Noopur Raval and Paul Dourish. 2016. Standing Out from the Crowd: Emotional Labor, Body Labor, and Temporal Labor in Ridesharing. In Proceedings of the 19th ACM Conference on Computer-Supported Cooperative Work \& Social Computing (CSCW'16). ACM, New York, NY, USA, 97-107. DOI : http://dx. doi . org/10.1145/2818048.2820026

58. Jo Rhodes. 2009. A strategic framework for rural micro-enterprise development: The integration of information communication technology (ICT), e-commerce, marketing, and actor-network theory. Perspectives on global development and technology 8,1 (2009), 48-69.

59. Lauren Rhue and Jessica Clark. 2016. Who Gets Started on Kickstarter? Racial Disparities in Crowdfunding Success. (9 Sep. 2016).

http://dx.doi.org/10.2139/ssrn. 2837042

60. Elena Rocco, Thomas A Finholt, Erik C Hofer, and JD Herbsleb. 2001. Out of sight, short of trust. In Presentation at the Founding Conference of the European Academy of Management. Barcelona, Spain.

61. Alex Rosenblat and Luke Stark. 2016. Algorithmic Labor and Information Asymmetries: A Case Study of Uber's Drivers. (2016).

62. Nithya Sambasivan, Ed Cutrell, Kentaro Toyama, and Bonnie Nardi. 2010. Intermediated technology use in developing communities. In Proceedings of the SIGCHI Conference on Human Factors in Computing Systems. ACM, 2583-2592.

63. DK Sarasvathy, Herbert A. Simon, and Lester Lave. 1998. Perceiving and managing business risks: Differences between entrepreneurs and bankers. Journal of economic behavior \& organization 33, 2 (1998), 207-225.

64. Gerry Segal, Dan Borgia, and Jerry Schoenfeld. 2005. The motivation to become an entrepreneur. International journal of Entrepreneurial Behavior \& research 11, 1 (2005), 42-57.

65. S.E. Shanahan and N.B. Tuma. 1994. The sociology of distribution and redistribution. In The handbook of economic sociology, N.J. Smelser and R. Swedberg (Eds.). Princeton University Press, Princeton, NJ, 733-765.

66. Scott Andrew Shane. 2003. A general theory of entrepreneurship: The individual-opportunity nexus. Edward Elgar Publishing. 
67. Nick Taylor, Ursula Hurley, and Philip Connolly. 2016. Making Community: The Wider Role of Makerspaces in Public Life. In Proceedings of the 2016 CHI Conference on Human Factors in Computing Systems (CHI'16). ACM, New York, NY, USA, 1415-1425. DOI : http://dx. doi .org/10.1145/2858036.2858073

68. Austin L. Toombs, Shaowen Bardzell, and Jeffrey Bardzell. 2015. The Proper Care and Feeding of Hackerspaces: Care Ethics and Cultures of Making. In Proceedings of the 33rd Annual ACM Conference on Human Factors in Computing Systems (CHI'15). ACM, New York, NY, USA, 629-638. DOI :

http://dx. doi . org/10.1145/2702123.2702522

69. Kentaro Toyama. 2015. Geek Heresy: Rescuing Social Change from the Cult of Technology. (2015).

http://www . amazon. com/

Geek-Heresy-Rescuing-Social-Technology/dp/161039528X
70. United States Census Bureau. 2015. Selected Economic Characteristics: 2010-2015 American Community Survey 5-Year Estimates. n.d. (2015).

https://factfinder. census.gov

71. William Foote Whyte (Ed.). 1991. Participatory action research. Sage Publications, Inc, Thousand Oaks, CA, US. 247 pages.

72. Hao Zhao, Scott E Seibert, and Gerald E Hills. 2005. The mediating role of self-efficacy in the development of entrepreneurial intentions. Journal of applied psychology 90, 6 (2005), 1265.

73. Jun Zheng, Elizabeth Veinott, Nathan Bos, Judith S. Olson, and Gary M. Olson. 2002. Trust without touch: jumpstarting long-distance trust with initial social activities. In Proceedings of the SIGCHI conference on human factors in computing systems. ACM, 141-146. 